\title{
Functional high-throughput screening reveals miR-323a-5p and miR-342-5p as new tumor-suppressive microRNA for neuroblastoma
}

\author{
Aroa Soriano ${ }^{1} \cdot$ Marc Masanas $^{1} \cdot$ Ariadna Boloix $^{1,2} \cdot$ Núria Masiá $^{3} \cdot$ Laia París-Coderch $^{1} \cdot$ Olga Piskareva $^{4}$. \\ Carlos Jiménez ${ }^{1} \cdot$ Kai-Oliver Henrich ${ }^{5}$. Josep Roma ${ }^{1}$. Frank Westermann ${ }^{5}$. Raymond L. Stallings ${ }^{4}$. \\ Constantino Sábado ${ }^{6}$. Josep Sánchez de Toledo ${ }^{1,6} \cdot$ Anna Santamaria $^{3}$ · Soledad Gallego ${ }^{1,6} \cdot$ Miguel F. Segura $^{1}$ (D)
}

Received: 1 October 2018 / Revised: 28 January 2019 / Accepted: 4 February 2019 / Published online: 15 February 2019

(c) The Author(s) 2019

\begin{abstract}
Current therapies for most non-infectious diseases are directed at or affect functionality of the human translated genome, barely $2 \%$ of all genetic information. By contrast, the therapeutic potential of targeting the transcriptome, $~ 70 \%$ of the genome, remains largely unexplored. RNA therapeutics is an emerging field that widens the range of druggable targets and includes elements such as microRNA. Here, we sought to screen for microRNA with tumor-suppressive functions in neuroblastoma, an aggressive pediatric tumor of the sympathetic nervous system that requires the development of new therapies. We found miR-323a-5p and miR-342-5p to be capable of reducing cell proliferation in multiple neuroblastoma cell lines in vitro and in vivo, thereby providing a proof of concept for miRNA-based therapies for neuroblastoma. Furthermore, the combined inhibition of the direct identified targets such as CCND1, CHAF1A, INCENP and BCL-XL could reveal new vulnerabilities of high-risk neuroblastoma.
\end{abstract}

Keywords Pediatric cancer · Non-coding RNA $\cdot$ High-throughput screening $\cdot 14 q 32 \cdot$ Epigenetics $\cdot$ Cancer therapy

\section{Introduction}

Aroa Soriano and Marc Masanas contributed equally to this work.

Electronic supplementary material The online version of this article (https://doi.org/10.1007/s00018-019-03041-4) contains supplementary material, which is available to authorized users.

Miguel F. Segura

miguel.segura@vhir.org

1 Group of Translational Research in Child and Adolescent Cancer, Vall d'Hebron Research Institute (VHIR)-

Universitat Autònoma de Barcelona (UAB), Passeig Vall d'Hebron 119-129, Collserola Building. Lab 207, 08035 Barcelona, Spain

2 Institut de Ciència de Materials de Barcelona (ICMAB-CSIC) and Nanomol Technologies SA, Mòdul de Recerca B, Campus UAB, 08193 Bellaterra, Spain

3 Cell Cycle and Cancer Laboratory, Biomedical Research Group in Urology, Vall d'Hebron Research Institute
Approximately 15,000 new cases of pediatric cancers are diagnosed yearly in Europe, with around 10\% corresponding to neuroblastoma (NB), an embryonal tumor of the sympathetic nervous system [1]. NB accounts for $15 \%$ of all cancer-related deaths in children, and is the embryonal tumor with the lowest 5-year relative survival [2]. Significant improvements are only foreseen in the field of new targeted

(VHIR)-Universitat Autònoma de Barcelona (UAB), Passeig Vall d'Hebron 119, 08035 Barcelona, Spain

4 Molecular and Cellular Therapeutics, Royal College of Surgeons in Ireland and National Children's Research Centre Our Lady's Children's Hospital, Dublin, Ireland

5 Neuroblastoma Genomics Group, German Cancer Research Center (DKFZ), Im Neuenheimer Feld 280, 69120 Heidelberg, Germany

6 Pediatric Oncology and Hematology Department, Hospital Universitari Vall d'Hebron-Universitat Autònoma de Barcelona (UAB), Passeig Vall d'Hebron 119, 08035 Barcelona, Spain 
therapies and personalized medicine programs which, at present, are effective for a small number of patients. Therefore, new approaches must be considered.

RNA therapeutics is an emerging field that widens the range of druggable targets and includes elements such as small interference RNA (i.e., siRNA, shRNA and microRNA). MicroRNA (miRNA) are small non-coding RNA that interfere with the translation and stability of coding mRNA in a sequence-specific manner [3]. Mounting evidence shows miRNA to be deregulated and functionally contributing to the development and progression of different human cancers, including NB $[4,5]$. An overall reduction in miRNA is observed in advanced NB, mainly due to alterations in the miRNA-processing machinery [6]; therefore, miRNA restoration represents an attractive novel therapeutic approach.

To identify miRNA with therapeutic potential in NB, we carried out high-throughput functional screening of 2048 miRNA mimics. Several miRNA with potential tumorsuppressive functions were identified, among which miR$323 a-5 p$ and miR-342-5p had the highest therapeutic potential in multiple NB cell lines in vitro and in vivo. These results support the use of miRNA-based restoration therapies as an alternative tool against NB resistant to conventional therapies.

\section{Materials and methods}

\section{Cell lines}

SK-N-AS, SH-SY5Y, IMR-32 and HEK293T cell lines were purchased from American Type Culture Collection (ATCC, Manassas, VA, USA), CHLA-90 cell line from the Children's Oncology Group Cell Culture and Xenograft Repository (Lubbock, TX, USA). SK-N-BE(2) and LA1-5s acquired from Public Health England Culture Collections (Salisbury, UK). All cell lines purchased from the tissue banks were amplified and stored in liquid nitrogen. Upon resuscitation, cells were maintained in culture for no more than 2 months. SK-N-AS, SK-N-BE(2), SH-SY5Y, IMR32, CHLA-90 and LA1-5s were cultured and maintained in Iscove's modified Dulbecco's medium (Life Technologies,
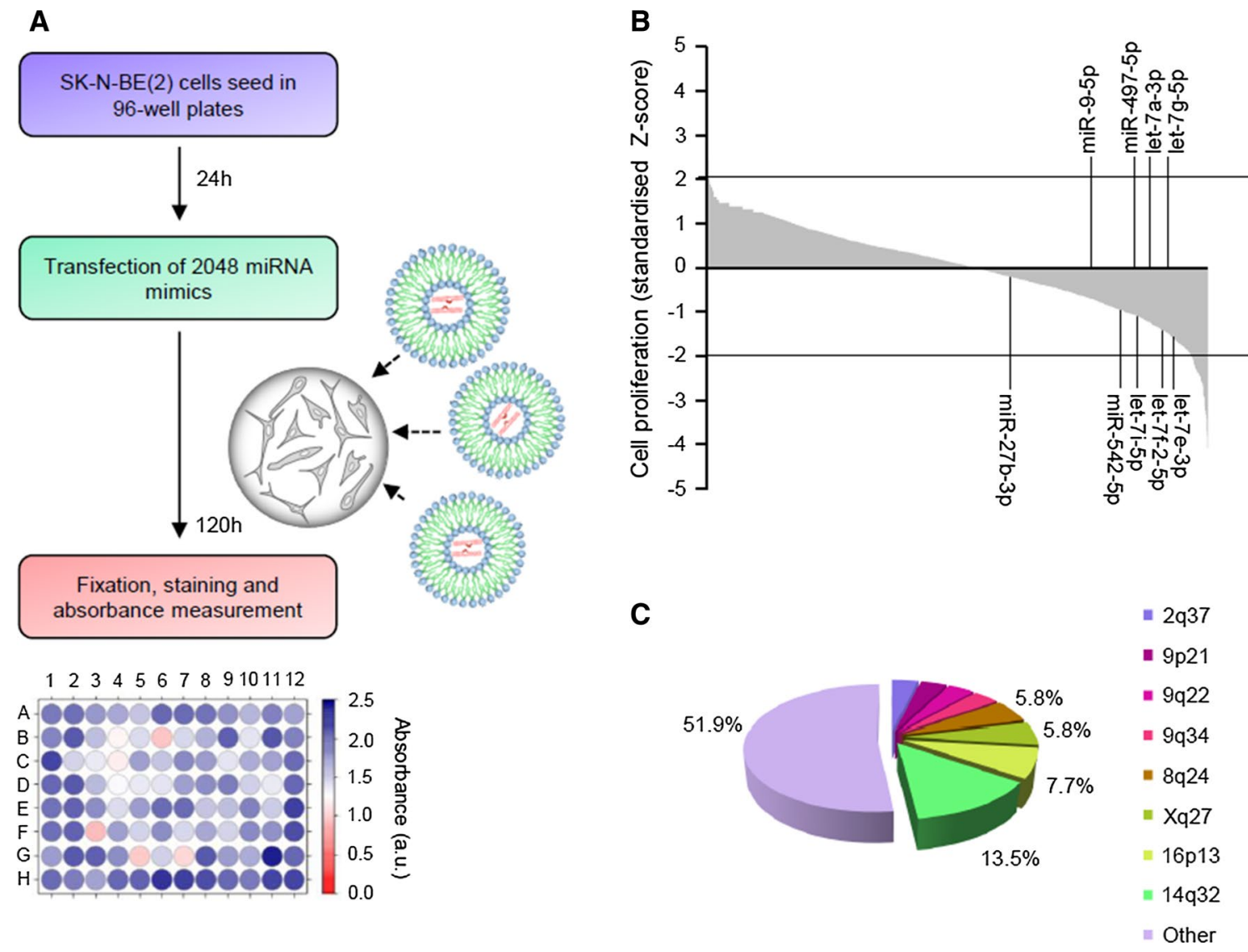

Fig. 1 Functional high-throughput miRNA screening identified several tumor-suppressive miRNA. a Screening design. b Graph representing the effects of 2048 individual miRNA on cell proliferation. The percentage of growth inhibition was obtained by comparing the average of three independent miRNA mimics replicates with mock-

transfected cells and standardized using the $Z$ score transformation method. MiRNA previously reported as tumor-suppressive miRNA in $\mathrm{NB}$ are indicated. $\mathbf{c}$ Pie chart representing the genomic distribution of miRNA that were capable of reducing cell proliferation $\sim 50 \%(Z$ score $<-2)$ 
Thermo Fisher Scientific) supplemented with 10\% heat-inactivated fetal bovine serum (South America Premium, Biowest) and 1\% of insulin-transferrin-selenium Supplement (Life Technologies, Thermo Fisher Scientific). HEK293T were grown in Dulbecco's modified Eagle's medium (Life Technologies, Thermo Fisher Scientific) supplemented with $10 \%$ heat-inactivated fetal bovine serum. All media were supplemented with $100 \mathrm{U} / \mathrm{mL}$ penicillin, $100 \mu \mathrm{g} / \mathrm{mL}$ streptomycin (Life Technologies, Thermo Fisher Scientific) and $5 \mu \mathrm{g} / \mathrm{mL}$ plasmocin (InvivoGen). All cultures were maintained at $37{ }^{\circ} \mathrm{C}$ in a saturated atmosphere of $95 \%$ air and $5 \%$ $\mathrm{CO}_{2}$. All cell lines were frequently tested for mycoplasma contamination.

\section{MicroRNA functional high-throughput library screening}

Chemoresistant SK-N-BE(2) cells were seeded in 96-well plates at 5000 cells/well using the MultidropV2 dispenser (Finstruments). Twenty-four hours later cells were transfected with a microRNA library consisting of 2048 human miRNA mimics (Dharmacon, Lafayette, CO, USA, miRIDIAN ${ }^{\circledR}$ microRNA Library-Human Mimic (19.0) CS-001030 Lot 13112, GE Healthcare, $25 \mathrm{nM}$ each miRNA) in technical triplicates using Lipofectamine 2000 (Life technologies, Thermo Fisher Scientific, Madrid, Spain, $0.2 \mu \mathrm{L}$ per well) using the Robotic Platform Caliper Sciclone (Caliper Life Sciences, Perkin Elmer, Waltham, Massachusetts, USA). At $96-\mathrm{h}$ post-transfection, cells were fixed with $1 \%$ glutaraldehyde (Sigma-Aldrich) and stained with $0.5 \%$ crystal violet (Sigma-Aldrich, Madrid, Spain). Crystals were dissolved with $15 \%$ acetic acid (Fisher Scientific) and absorbance was measured at $590 \mathrm{~nm}$ using an Epoch Microplate Spectrophotometer (Biotek, Winooski, Vermont, USA).

\section{Screening statistics}

Data quality control and analysis of different factors (e.g., miRNA position, transfection time) was performed using "R" Statistical Software (Supplementary Fig. 1C).

The absorbance value of each mock- or miRNA-transfected well was normalized to the median of all nontransfected values of the corresponding replicate plate. To evaluate the effect of each miRNA on cell proliferation, the absorbance value ( 3 replicates) versus the median of all mock values was compared. The statistical significance was assessed by Student's $t$ test and the $p$ value was adjusted by the false discovery rate "FDR" method. The percentage of
A
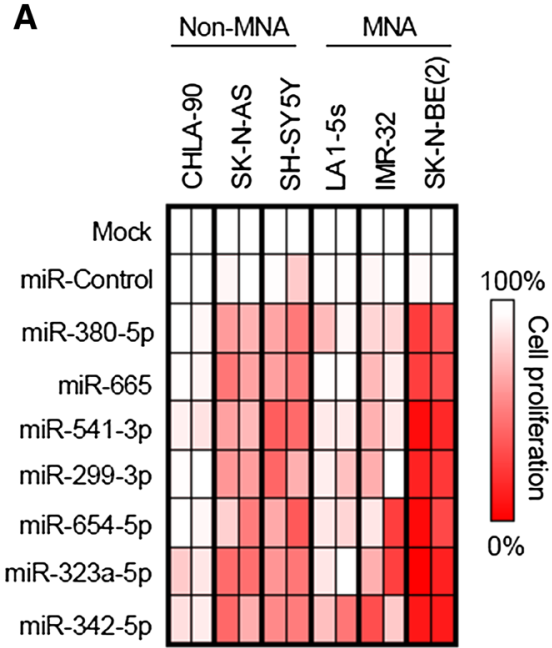

B $\widehat{3}$

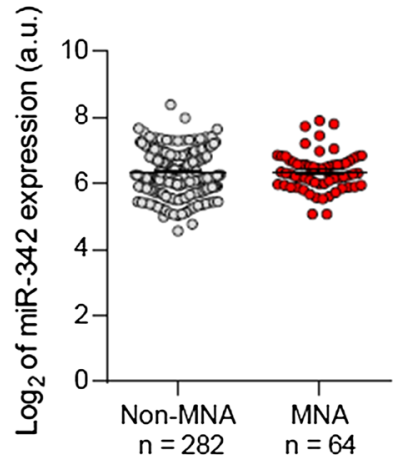

D

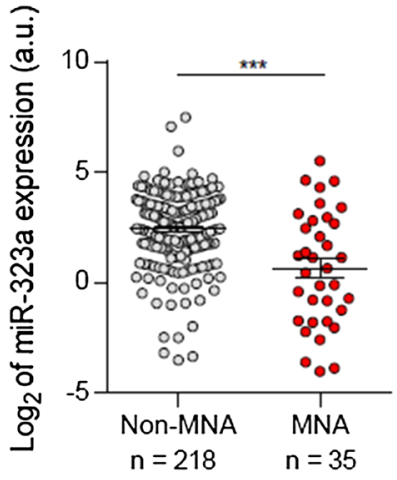

C

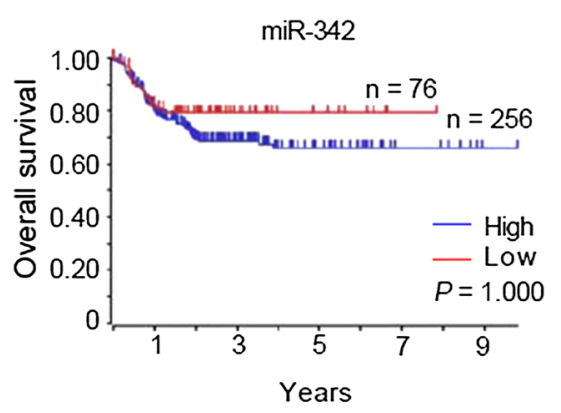

$\mathbf{E}$

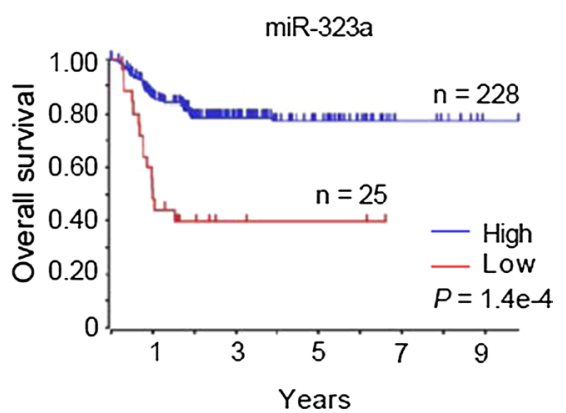

Fig. 2 Ectopic expression of miRNA located at $14 \mathrm{q} 32$ reduced cell proliferation in multiple NB cell lines. a Heatmap representing effects of the indicated miRNA on cell proliferation reduction in MYCN amplified (MNA) and MYCN non-amplified (non-MNA) cell lines. The overexpression effect of each miRNA on cell proliferation was compared to mock-transfected cells. b, d Relative expression $\left(\log _{2}\right)$ of miR-342 (b) and miR-323a (d) in MNA and non-MNA NB tumors. c, e Overall survival Kaplan-Meier plot of the indicated miRNA expression in human NB tissues 

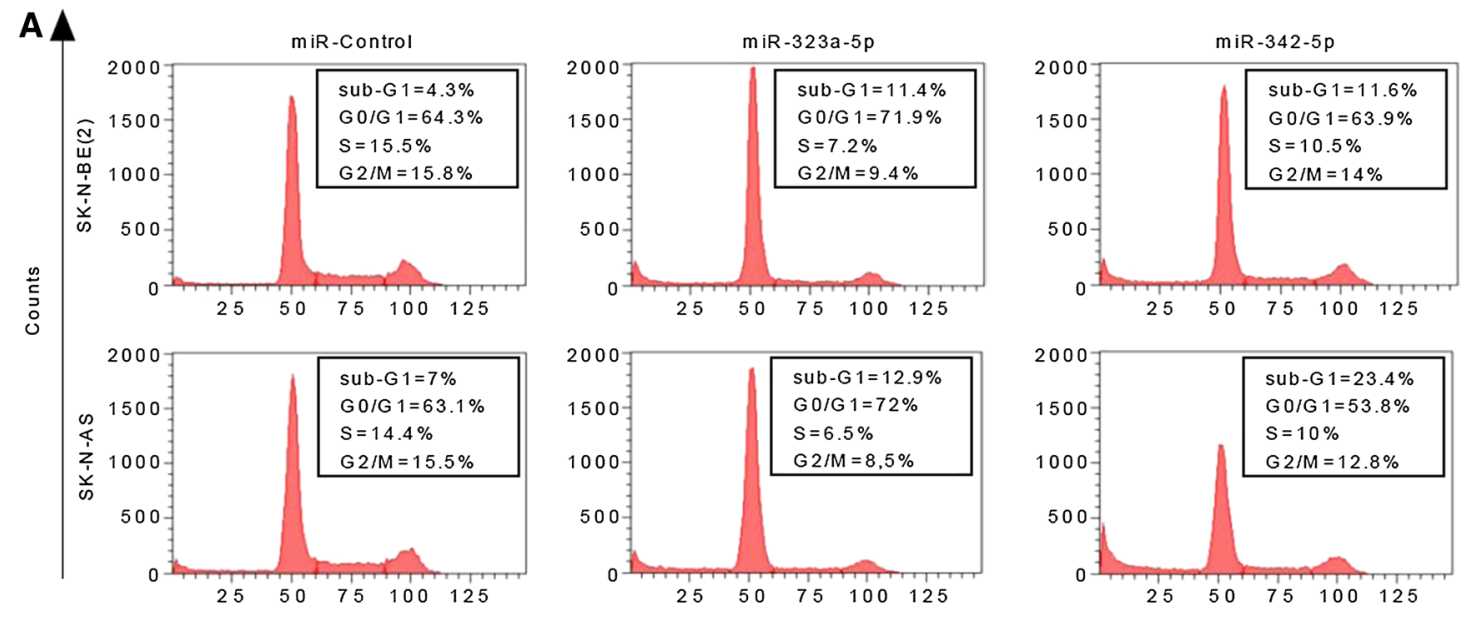

DNA content

B

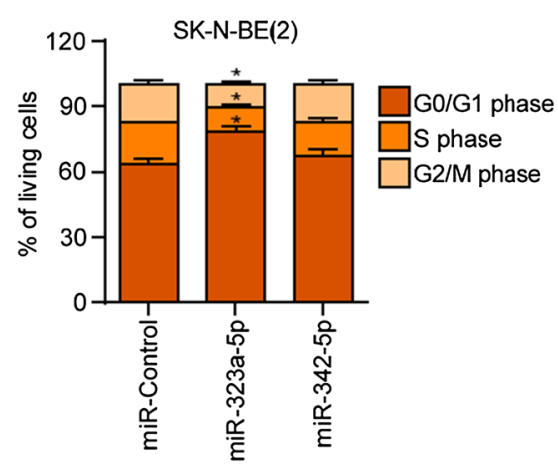

miR-Control miR-323a-5p miR-342-5p

\begin{tabular}{l|l|l|l} 
G0/G1 phase & $63.7 \pm 2.3$ & $78.5 \pm 2.4$ & $67.0 \pm 3.4$ \\
\hline S phase & $18.7 \pm 0.5$ & $10.9 \pm 1.2$ & $16.1 \pm 1.6$ \\
\hline G2/M phase & $17.5 \pm 1.9$ & $10.6 \pm 1.3$ & $17.0 \pm 1.9$
\end{tabular}

D

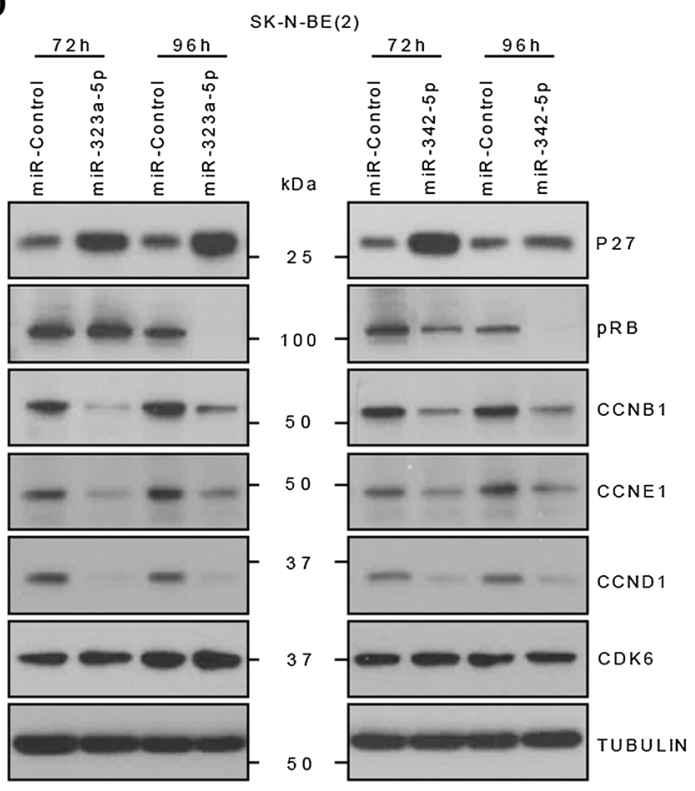

C

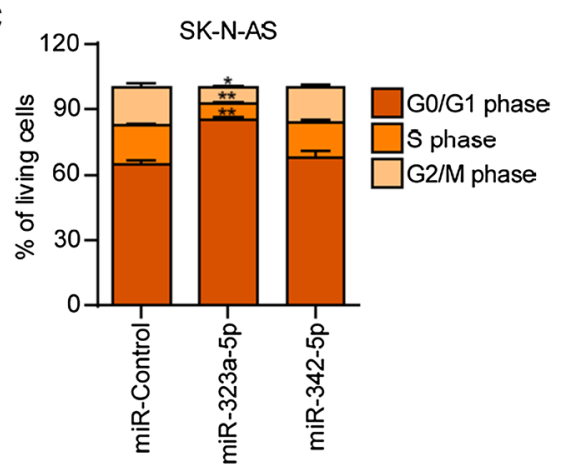

miR-Control miR-323a-5p miR-342-5p \begin{tabular}{l|l|l|l} 
G0/G1 phase & $64.8 \pm 1.8$ & $85.3 \pm 1.3$ & $67.4 \pm 3.0$ \\
\hline
\end{tabular}

\begin{tabular}{l|r|r|r}
\hline S phase & $17.8 \pm 0.5$ & $7.3 \pm 0.9$ & $16.0 \pm 1.8$ \\
\hline
\end{tabular}

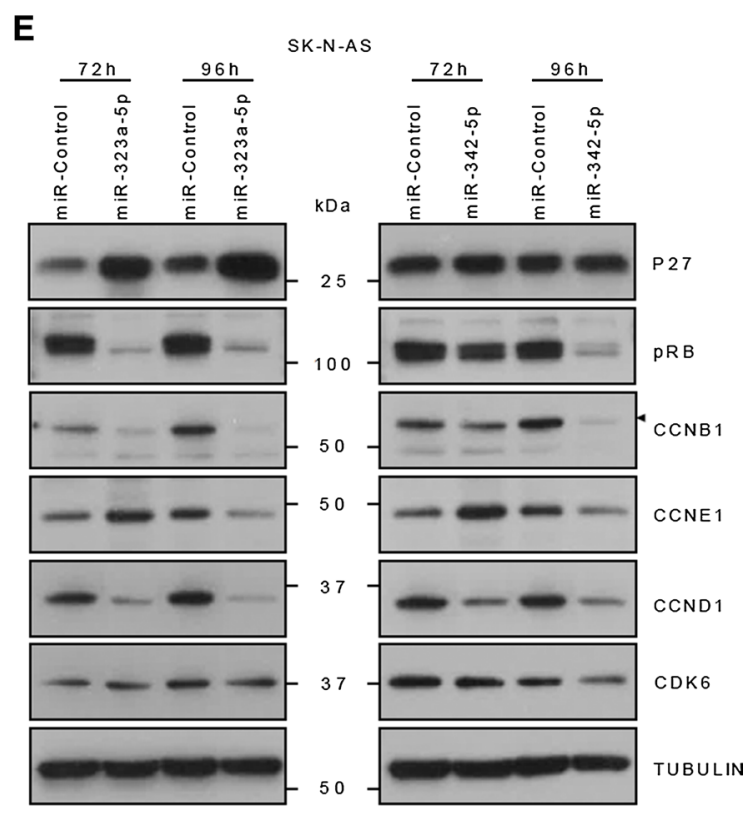


4Fig. 3 MiR-323a-5p induced cell cycle arrest at G0/G1 phase. Cell cycle flow cytometry analysis of the indicated cell lines transfected with miR-control, miR-323a-5p or miR-342-5p at $25 \mathrm{nM}$ for $96 \mathrm{~h}$. a One representative histogram of three independent experiments. b, c Histograms representing the average percentage of living cell population from three independent experiments of SK-N-BE(2) (b) or SK$\mathrm{N}-\mathrm{AS}$ (c) cells in G0/G1, S, or G2/M phases. ${ }^{*} p<0.05, * * p<0.01$, two-tailed Student's $t$ test. d, e Western blot of the indicated cell cycle regulatory proteins in SK-N-BE(2) (d) and SK-N-AS (e) transfected with miR-control, miR-323a-5p and miR-342-5p (25 nM) at $72 \mathrm{~h}$ and $96 \mathrm{~h}$ post-transfection

proliferation was standardized using the $Z$ score equation $Z=\frac{x-\mu}{\sigma}$, where $x$ is the value of cell proliferation after transfection of each single miRNA, $\mu$ is the mean cell proliferation of all miRNA and $\sigma$ the standard deviation.

\section{Mouse xenograft}

SK-N-AS cells $\left(4 \times 10^{6}\right)$ were reverse transfected with $25 \mathrm{nM}$ of miR-control, miR-323a-5p or miR-342-5p in 100$\mathrm{mm}$ plates $(25 \mu \mathrm{L}$ lipofectamine/dish). SK-N-BE(2) cells $\left(4.7 \times 10^{6}\right)$ were reverse transfected with $25 \mathrm{nM}$ of miRcontrol, miR-323a-5p or miR-342-5p in T175 flasks $(90 \mu \mathrm{L}$ lipofectamine/flask). Thirty-six hours post-transfection, $4 \times 10^{6}$ cells/flank of SK-N-AS and $5 \times 10^{6}$ cells/flank of SK$\mathrm{N}-\mathrm{BE}(2)$ were injected into the right flank of 6- to 8-week-old female NMRI-nude mice ( $n=13$ mice/condition of SK-N-AS and $n=15$ mice/condition of SK-N-BE(2)) (Janvier Labs, Le Genest-Saint-Isle, France) in $300 \mu \mathrm{L}$ of PBS:Matrigel (1:1). Tumor volume was measured every 2-3 days. At the end of the experiment, the primary tumors were removed and weighted. Part of the tumors were fresh frozen and the rest fixed in $10 \%$ formalin and embedded in paraffin.

\section{Statistical methods}

Unless otherwise stated, mean \pm SEM values are representative of the average of three independent experiments. Statistical significance was determined by unpaired twotailed Student's $t$ test (GraphPad Prism Software, La Jolla, CA, USA.). * Means $p<0.05$, ** means $p<0.01$ and $* * *$ means $p<0.001$.

\section{Results}

\section{Functional high-throughput miRNA screening identified several miRNA with tumor-suppressive activity}

High-throughput screening using the largest library of miRNA mimics available was performed to identify miRNA with tumor-suppressive functions in NB. Individual miRNA mimics were transfected into the SK-N-BE(2) cells (Fig. 1a). Control miRNA (i.e., cel-miR-67 and cel-miR-239b) were used as negative controls and miR-497-5p as a positive control [7, 8] (Supplementary Fig. 1a,b). The overexpression of 52 miRNA was found to reduce $\sim 50 \%$ cell proliferation $(Z$ score $<-2$, adjusted $p$ value $<0.05$ ) (Fig. 1b; Supplementary Tables 1,2).

Since it has been suggested that miRNA with similar functions cluster together [9], we examined the genomic distribution of miRNA whose overexpression produced the highest reduction on cell proliferation. Interestingly, 7 of the 52 miRNA (13.5\%) were located at 14q32 (Fig. 1c and Supplementary Table 2), a locus with high miRNA density and frequently lost or silenced in different types of tumors, including NB [10].

\section{Restoration of miRNA located at $14 q 32$ reduced cell viability in multiple NB cell lines}

The tumor-suppressive effects of miRNA hits located at 14q32 (i.e., miR-380-5p, miR-665, miR-541-3p, miR299-3p, miR-654-5p, miR-323a-5p and miR-342-5p) were further confirmed in an extended panel of six NB cell lines bearing genomic alterations associated with resistance to standard NB therapies and poor patient outcome (Supplementary Table 3). The overexpression of all miRNA tested reduced cell proliferation in multiple NB cell lines compared with mock- and miR-control-transfected cells being miR-323a-5p and miR-342-5p those ones with the highest therapeutic potential (Fig. 2a).

\section{Low miR-323a-5p expression levels correlate with poor patient outcome}

The expression levels of miR-323a-5p and miR-342-5p were analyzed in a large cohort of NB tissue samples and correlated with clinical parameters. Whereas lower expression levels of miR-342-5p did not correlate with the clinical parameters analyzed (Fig. 2b-c), low miR-323a-5p levels were found to correlate with MYCN genomic amplification (Fig. 2d) and shorter overall survival (Fig. 2e).

\section{Ectopic expression of miR-323a-5p and miR-342-5p halted cell cycle progression and induced apoptosis in NB}

To clarify whether the reduction in cell number upon miR323a-5p and miR-342-5p overexpression was due to inhibition of cell proliferation and/or induction of cell death, cell cycle progression was analyzed using flow cytometry. The overexpression of miR-323a-5p induced a modest increase 

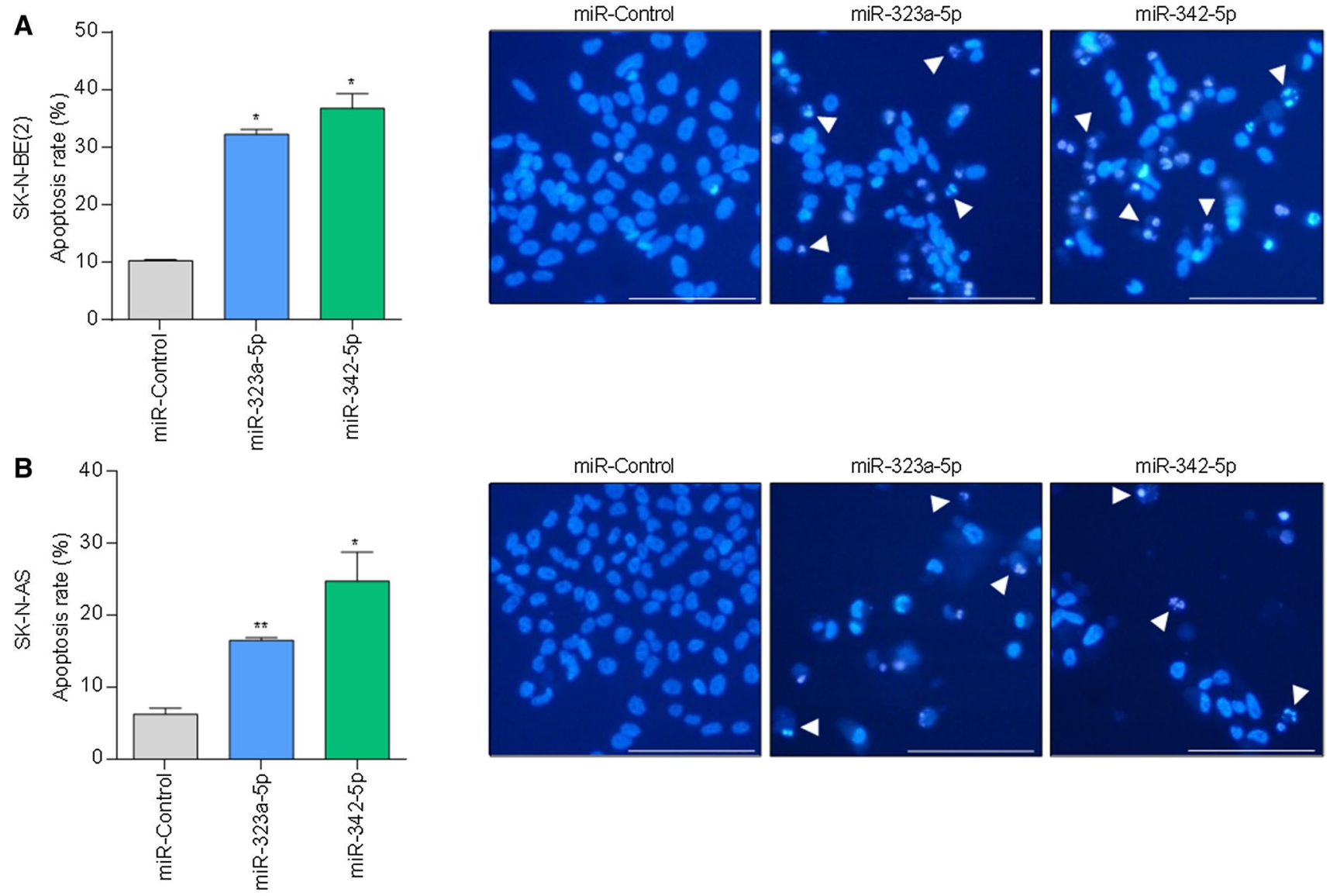

C

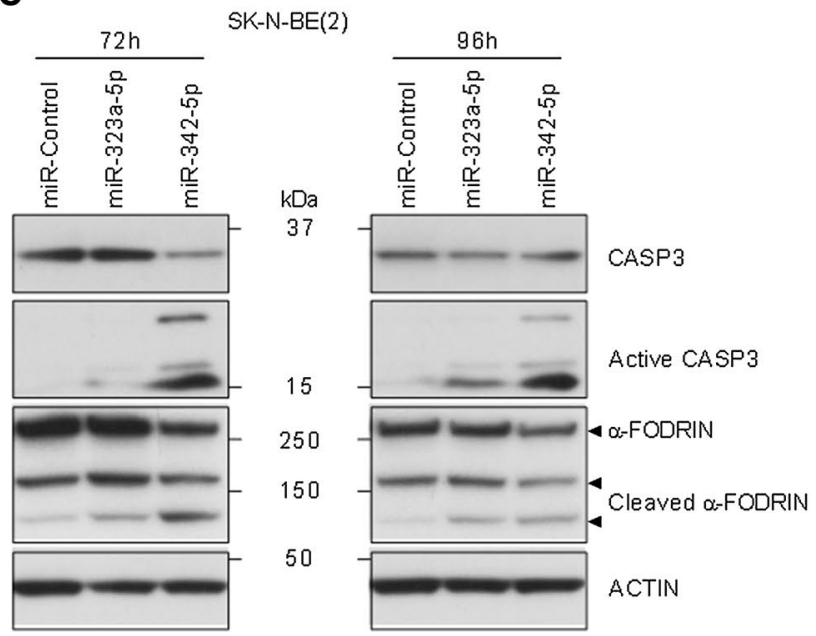

Fig. 4 MiR-323a-5p and miR-342-5p overexpression induced apoptosis in NB cells. a, b Analysis of chromatin fragmentation/condensation in SK-N-BE(2) (a) and SK-N-AS (b) transfected with $25 \mathrm{nM}$ of miR-control, miR-323a-5p or miR-342-5p $96 \mathrm{~h}$ post-transfection. Images on the right show a representative field of NB cells stained with Hoechst dye. White arrowheads point to cells with condensed
D

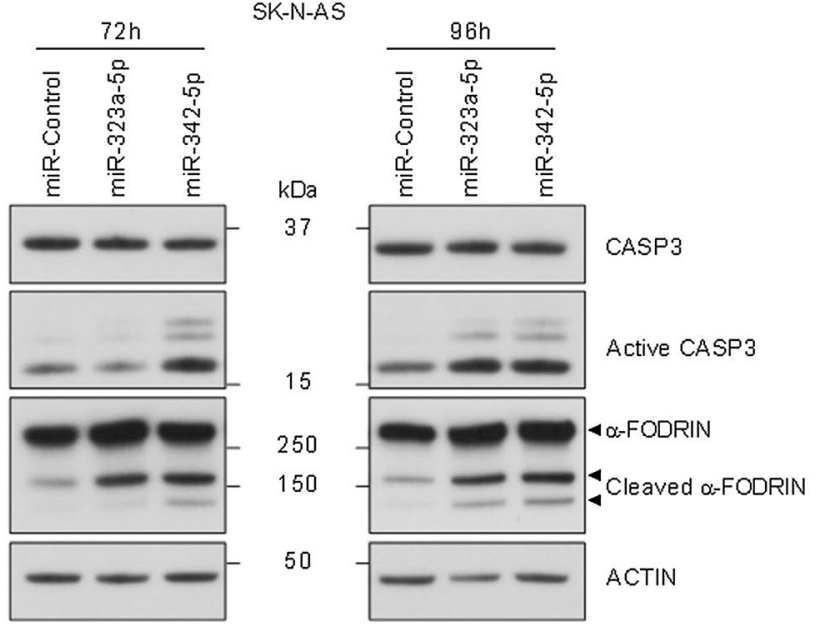

and/or fragmented chromatin. Data represent mean \pm SEM of three independent experiments $\left(n=3\right.$ per experiment). ${ }^{*} p<0.05$, $*^{*} p<0.01$, two-tailed Student's $t$ test. c, d Representative Western blot analysis of apoptosis-related proteins in SK-N-BE(2) (c) and SK$\mathrm{N}-\mathrm{AS}$ (d) transfected with miR-control, miR-323a-5p or miR-342-5p $(25 \mathrm{nM})$ at $72 \mathrm{~h}$ and $96 \mathrm{~h}$ post-transfection 
in the subG1 peak and an increment in G0/G1-phase population accompanied by a reduction in the $\mathrm{S}$ and $\mathrm{G} 2 / \mathrm{M}$ phases. Therefore, both cell cycle arrest and increased cell death might be contributing to the miR-323a-5p overexpression phenotype (Fig. 3a-c). Concurring with these observations, a reduction in cyclins, D1, E1 and B1 was observed after miR-323a-5p overexpression at $72 \mathrm{~h}$ post-transfection and a consequent reduction in phospho-RB levels at later time points. Furthermore, upregulation of the cell cycle inhibitor p27 was also observed (Fig. 3d, e).

MiR-342-5p-transfected cells showed no apparent differences regarding cell cycle progression compared to miR-control cells, but did show an accumulation of cells in subG1, thereby indicating cell death induction (Fig. 3a-c). In this case, reduced levels of cyclins, D1, E1 and B1 and phospho-RB, but not increased p27 levels, were also observed (Fig. 3d, e), suggesting that cells committed to die were unable to progress through the cell cycle.

Next, we examined the chromatin status of miRNAtransfected cells by Hoechst staining. MiR-323a-5p and miR-342-5p transfected cells showed a higher percentage of cells with condensed and fragmented chromatin staining, one of the typical hallmarks of apoptosis (Fig. 4a, b). Furthermore, NB cells transfected with miR-323a-5p and miR-342-5p showed cleavage of the executor caspase- 3 and one of its targets $\alpha$-FODRIN, both indicative of apoptotic cell death (Fig. 4c, d).

\section{MiR-323a-5p and miR-342-5p target cell cycle and survival genes}

To find the downstream mediators of miR-323a-5p and miR342-5p phenotypic effects in NB, a miRNA-target analysis was performed comparing five different platforms (Fig. 5a, b). For miR-323a-5p, 905 potential targets were predicted by at least four independent algorithms, whereas 1380 were predicted for miR-342-5p (Supplementary Tables 4, 5). According to the Kyoto Encyclopedia of Genes and Genomes (KEGG) pathway analysis [11], a significant number of these predicted targets were associated with cell cycle or commonly altered pathways in cancer (Fig. 5c, d, $p$ value $<0.05)$. These genes were selected for validation based on their expression association with NB outcome and/or previous reported functional role in cancer (Supplementary Tables 6,7 ). Transient miRNA overexpression proved to consistently reduce the mRNA levels of several miR-323a-5p (i.e., CHAF1A, KIF11, INCENP, CDC25A, $C C N D 1, F A D D$ and $E 2 F 2$ ) and miR-342-5p (i.e., $A K T 2$, $C C N D 1, M K N K 2$ and $B C L X$ ) predicted targets (Supplementary Fig. 2a-d). To confirm the reduction also in protein levels, Western blot was performed at $48 \mathrm{~h}$ and $72 \mathrm{~h}$ post-transfection of miR-323a-5p or miR-342-5p. CHAF1A, KIF11, INCENP, CDC25A, CCND1 and FADD protein levels decreased in both cell lines when cells were transfected with miR-323a-5p (Fig. 5e). On the other hand, only CCND1 and BCL-XL protein levels were reduced in both cell lines when cells were transfected with miR-342-5p, whereas no differences were found in AKT2 levels. Results for MKNK2 were not conclusive (Fig. 5f).

To ascertain whether the potential targets were regulated directly by miR-323a-5p or miR-342-5p, we engineered luciferase-reporter vectors with the 3'UTR of genes bearing the putative miRNA-binding sites (Supplementary Fig. 3). The reporter vectors were co-transfected with a miR-control, miR-323a-5p or miR-342-5p and luciferase activity was quantified $24 \mathrm{~h}$ after transfection. The overexpression of miR-323a-5p caused a reduction in luciferase activity in the CHAF1A, INCENP, CCNDI and FADD 3'UTR reporter vectors and no differences were observed for KIFII and $C D C 25 A$, thereby indicating that these last two genes are not direct targets (Fig. $5 \mathrm{~g}$ ). On the other hand, reduction in the luciferase activity of $C C N D 1$ and $B C L X 3^{\prime} \mathrm{UTR}$ vectors by miR-342-5p overexpression confirmed both genes as direct miR-342-5p targets (Fig. 5h).

\section{CCND1, CHAF1A and INCENP silencing mostly reproduced miR-323a-5p overexpression effects}

The contribution of each target to the miRNA overexpression phenotype was analyzed by siRNA-mediated gene silencing. Silencing of CHAF1A, KIF11 and CCND1 showed a reduction in cell proliferation similar to that induced by miR-323a-5p, while INCENP and FADD silencing only produced a moderate effect (Fig. 6a). Western blot analysis $72 \mathrm{~h}$ post-transfection confirmed siRNA efficacy (Fig. 6a, lower panels). Overall, CCND1 depletion mirrored the best miR-323a-5p overexpression, not only the general effects on cell proliferation, but also on the reduction in phosphoRB levels and p27 accumulation (Fig. 6b). However, when apoptosis induction was analyzed, CHAF1A and INCENP were the direct targets that better phenocopied the effects of miR-323a-5p overexpression (Fig. 6c). These results suggest that the combination of CCND1, CHAF1A and INCENP inhibition is sufficient to reproduce the therapeutic effects of miR-323a-5p.

\section{Inhibition of CCND1 and BCL-XL partially reproduces the effects of miR-342-5p}

The same strategy was used to characterize the contribution of miR-342-5p targets. In this case, only the inhibition of CCND1 showed a similar reduction in cell proliferation (Fig. 6d). In agreement with this observation, only CCND1 silencing caused a reduction in phospho-RB levels and accumulation of the cell cycle inhibitor p27 (Fig. 6e). However, apoptosis induction was not observed with silencing 


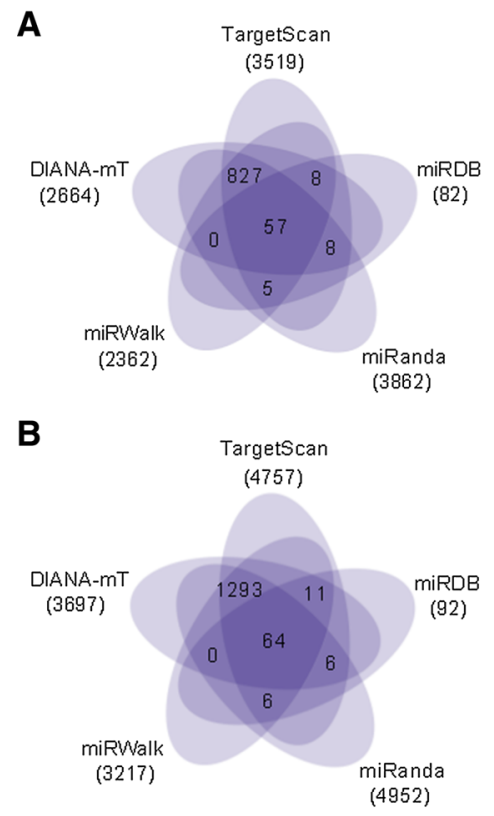

E

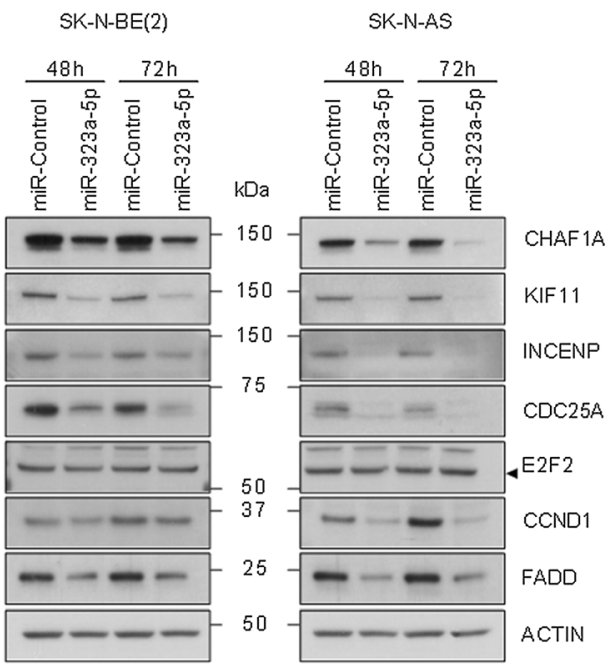

G

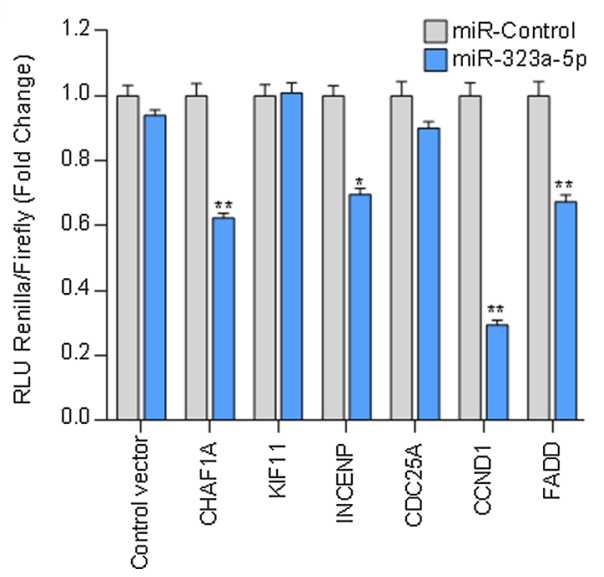

C

D

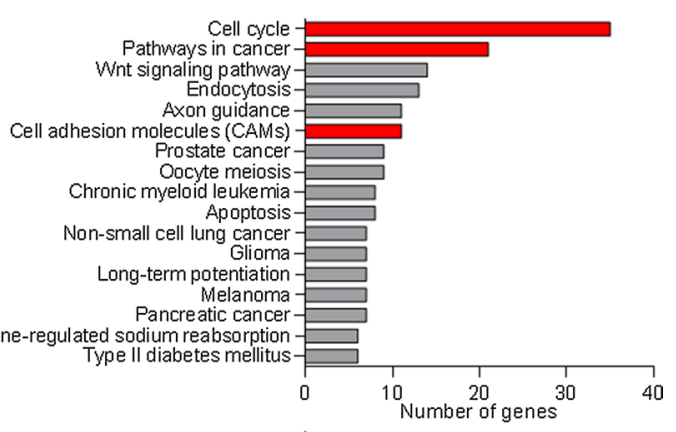

Pathways in cancer
MAPK signaling pathway

Regulation of Focal adhesioncytoskeleton

Insulin signaling pathway-

Acute myeloid leukemia

ARVC-
Prostate cancer-

ECM-receptor interaction-

Hypertrophic cardiomyopathy

Non-small cell lung cancer-

Glycerophospholipid metabolism-

Endometrial cancer-

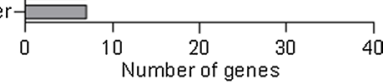

F

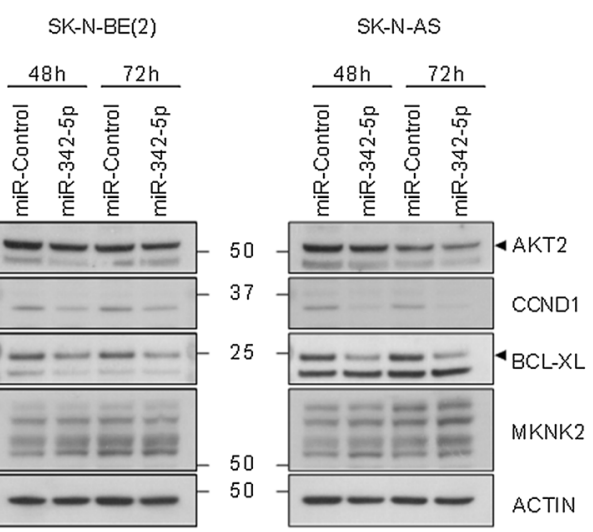

H

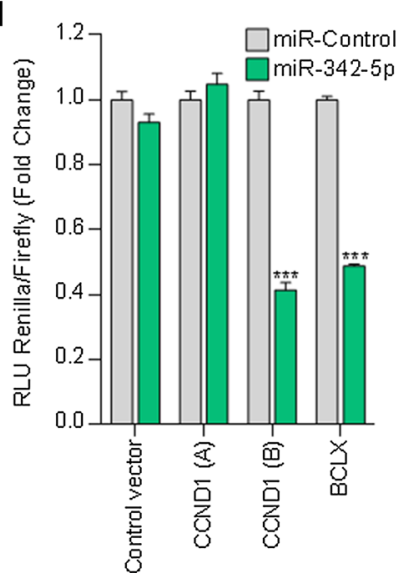


4Fig. 5 MiR-323a-5p and miR-342-5p modulated the expression of multiple cancer-related genes. a, b Venn diagram representing the overlap of predicted target genes among five miRNA-target prediction algorithms of miR-323a-5p or miR-342-5p. c, d Representation of the functional annotation of predicted target genes of miR-323a-5p (c) or miR-342-5p (d) using KEGG pathways and Gene Ontology databases. Red bars indicate selected pathways to analyze potential miRNA targets. e, f Representative Western blot of predicted target genes in SK-N-BE(2) and SK-N-AS transfected with miR-control, miR-323a-5p (e) or miR-342-5p (f) at $48 \mathrm{~h}$ and $72 \mathrm{~h}$ post-transfection. g, h Luciferase $3^{\prime}$ UTR reporter assays. Graph represents luciferase activity in HEK-293T cells co-transfected with $50 \mathrm{ng} / \mathrm{well}$ of the indicated reporter vectors and $25 \mathrm{nM}$ of miR-control, miR-323a-5p (g) or miR-342-5p (h). Data represented the average \pm SEM of three independent experiments $(n=3$ per experiment). $* p<0.05, * * p<0.01$, $* * * p<0.001$

of either CCND1 or BCL-XL (Fig. 6f) suggesting that the observed effects of miR-342-5p on cell death might require the inhibition of both or additional targets.

\section{MiR-323a-5p and miR-342-5p overexpression reduced tumor growth in vivo}

We proceeded to validate the capacity of miR-323a-5p and miR-342-5p to reduce tumor growth in vivo by subcutaneous injection of SK-N-BE(2) or SK-N-AS cells previously transfected with miR-control, miR-323a-5p or miR-342-5p into the flank of NRMI-nude mice. At the end of the experiment, all groups showed a similar percentage of tumor incidence ( 80-100\%, Fig. 7a, e), which suggested that miRNA overexpression did not interfere with tumor engraftment. Tumor growth was monitored every 2-3 days for 28 days for SK-N$\mathrm{BE}(2)$ or 18 days for SK-N-AS. While in SK-N-AS, only the overexpression of miR-342-5p was capable of delaying cell growth in vivo, both miRNA were effective in SK-N-BE(2) cells, showing a final $\sim$ twofold reduction in tumor growth at the end of the experiment (Fig. 7b, f). These effects were confirmed by the analysis of tumor weight (Fig. 7c, d, g, h-Supplementary Fig. 4a, b).

In summary, our results confirm miR-323a-5p and miR$342-5 p$ as potential therapeutic tools against high-risk NB. Of note, miR-323a-5p overexpression impaired tumor growth in the MYCN-amplified cell line, but not in SK-N-AS, suggesting that higher doses of miR-323a-5p or being functional for longer periods of time may be needed to achieve a therapeutic effect. In support of this hypothesis, miRNA levels were analyzed at the beginning and at the end of experiment. Both cell lines achieved similar levels of miRNA overexpression at the time of injection (Supplementary Fig. 5a, c) ruling out the possibility of differential transfection efficiency between cell lines. However, at the end of experiment, SK-N-AS maintained much lower levels of miR-323a-5p in SK-N-AS but not in SK-N-BE(2) (Supplementary Fig. 5b, d), thus suggesting that this miRNA is processed faster in this cell line and therefore, tumor cells overcome more easily the miR-323a-5p tumorsuppressive effects.

\section{Discussion}

Despite the emerging personalized medicine programs for pediatric tumors, which include molecular profiling of NB, the small number of recurrent somatic mutations found at diagnosis and the lack of established tumor drivers, limit the therapeutic opportunities for NB patients. On the other hand, some patients relapse and develop drug resistance when treated with anticancer drugs targeting single molecules, which might be due to the activation of alternative pathways.

MiRNA alterations have been shown to participate in the progression and outcome of NB (reviewed in [12]). We propose the use of miRNA as multi-target approach to overcome treatment resistance in NB patients, given that a single miRNA can inhibit multiple targets involved in tumorigenic processes.

Multiple pharmaceutical companies have already included miRNA in their developmental drug pipelines (e.g., miR-34 [13, 14], miR-16 [15], miR-122 [16]). The first challenge in applying this approach to the treatment of high-risk NB is to identify those miRNA with the highest therapeutic potential. Our work is the largest high-throughput functional screening performed to date to identify miRNA with tumor-suppressive functions in cancer and particularly for NB. Of the 2048 miRNA tested, we identified 52 that significantly reduced cell proliferation with a $Z$ score lower than -2 ( $50 \%$ of cell proliferation). Concurring with previous reports, multiple tumor-suppressive miRNA such as members of the let-7 miRNA tumorsuppressive family (e.g., let-7i-5p, let-7a-3p, let-7f-2-5p, let- $7 g-5 p$ or let-7e-3p $[17,18]$ ) were also identified in our screening, thereby validating our approach to identifying tumor-suppressive miRNA.

Notably, 7 of the 52 miRNA ( $13.5 \%$ of the total) shown to reduce cell proliferation $\sim 50 \%$ are encoded in the $14 \mathrm{q} 32$ genomic region. This region is frequently altered in cancer and particularly in NB [10], which raises the possibility that this region contains tumor-suppressor genes. All 7 miRNA identified in our screening showed the capacity to reduce cell proliferation in multiple NB cell lines in vitro, with miR-323a-5p and miR-342-5p being those with the highest therapeutic potential.

In agreement with our results, miR-323a-5p has been reported to be downregulated in NB patients with MYCN amplification and associated with unfavorable outcome $[19,20]$. Moreover, miR-323a-5p overexpression has been reported to reduce proliferation and promote apoptosis of human cerebral glioma cells [21]. We found that ectopic expression of miR-323a-5p suppressed cell growth through 
A SK-N-BE(2)
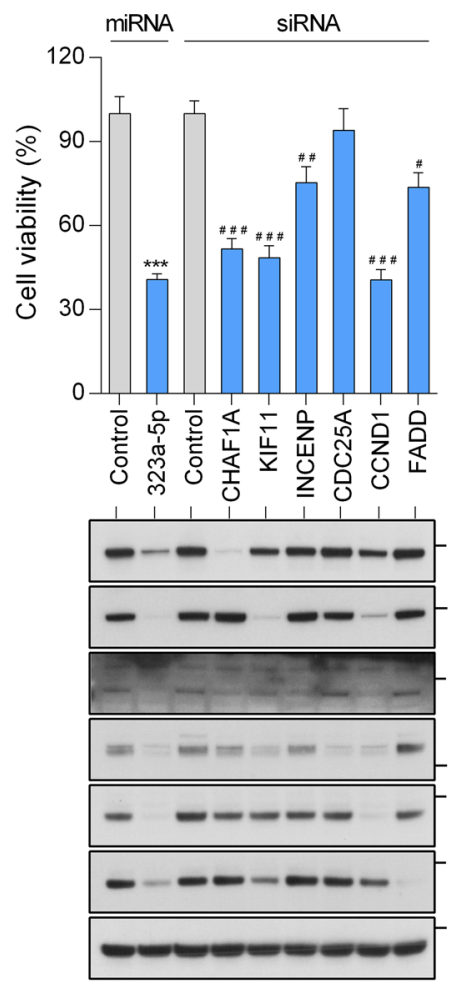

$\mathrm{kDa}$
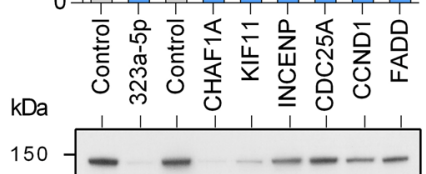
150
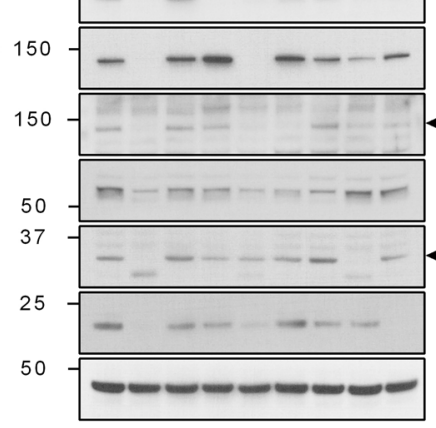

B
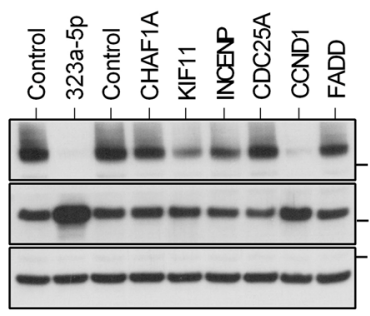

$\mathrm{kDa}$

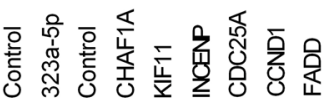

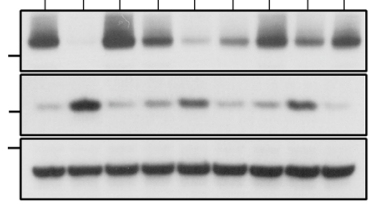

C

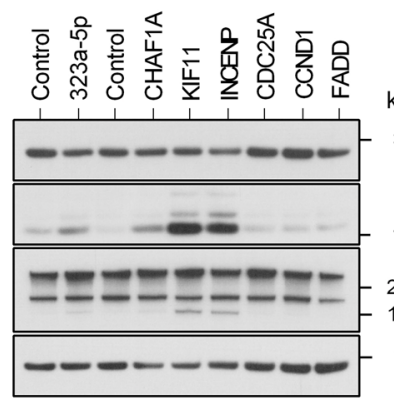

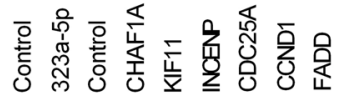

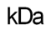

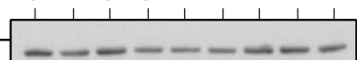
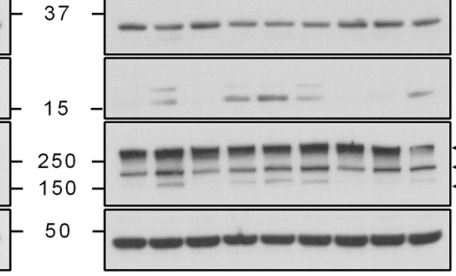

D

SK-N-BE(2)

SK-N-AS
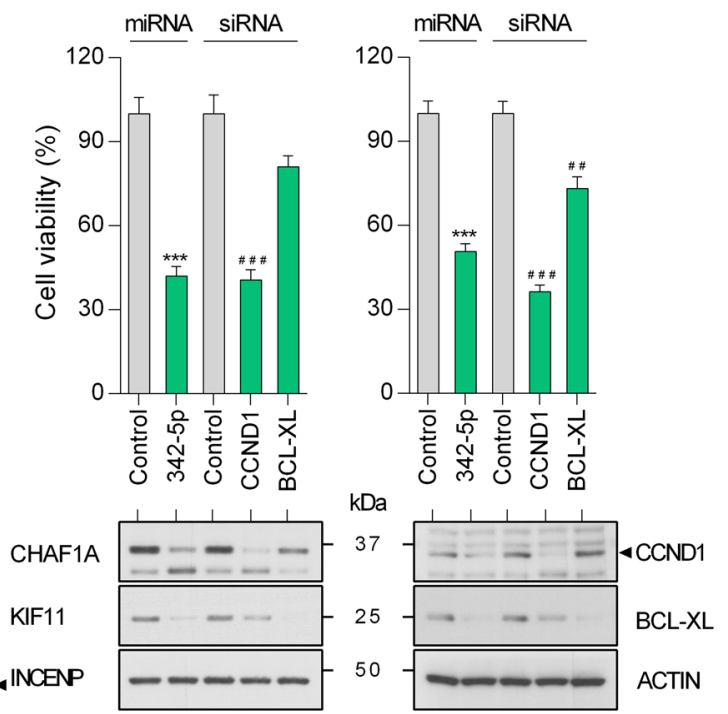

CDC25A E

CCND1

FADD

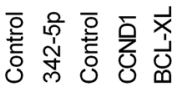

ACTIN

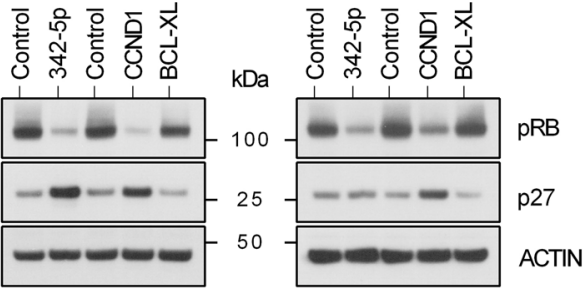

F

$\mathrm{pRB}$

p27

ACTIN
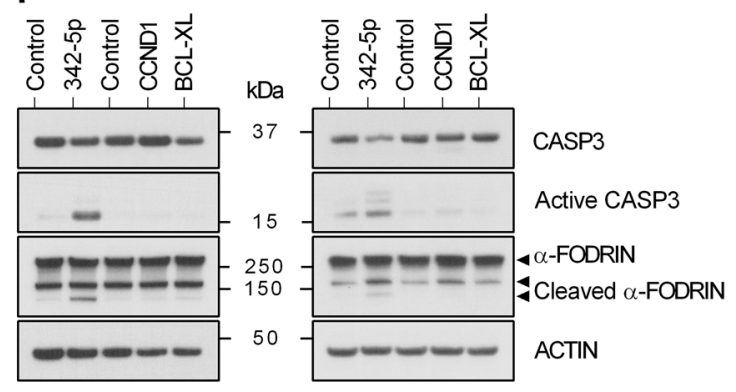

CASP3

Active CASP3

$\alpha-F O D R I N$

Cleaved $\alpha$-FODRIN

ACTIN

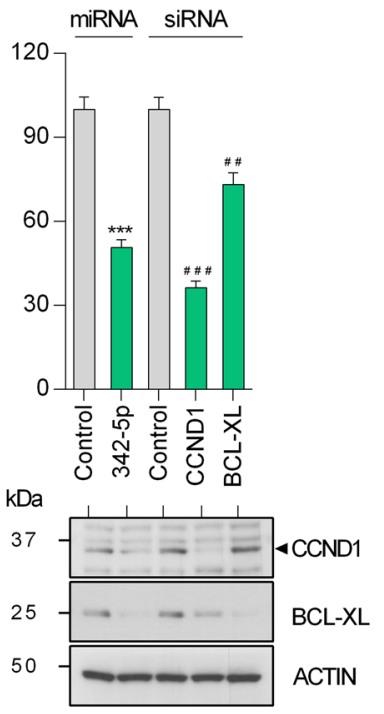

TIN

tion. c, $\mathbf{f}$ Western blot analysis of apoptosis-related proteins in SK$\mathrm{N}-\mathrm{BE}(2)$ and SK-N-AS transfected with miR-323a-5p, miR-342-5p or the indicated siRNA $(25 \mathrm{nM})$ at $96 \mathrm{~h}$ post-transfection. Graph represents one of three independent experiments ( $n=6$ per experiment). Asterisk compares miR-323a-5p or miR-342-5p versus miR-Control and hash compares each siRNA versus control siRNA. * or ${ }^{\#} p<0.05$,

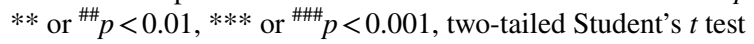

Fig. 6 MiRNA target-knockdown partially reproduced the antitumoral effects of miR-323a-5p and miR-342-5p. a, d Cell viability assay of SK-N-BE(2) and SK-N-AS transfected with $25 \mathrm{nM}$ of miR$323 a-5 p$, miR-342-5p or the indicated siRNA. Target protein knockdown was analyzed by Western blot at $72 \mathrm{~h}$ post-transfection (lower panels). b, e Expression of some representative cell cycle regulatory proteins in SK-N-BE(2) and SK-N-AS transfected with miR-323a-5p, miR-342-5p or the indicated siRNA $(25 \mathrm{nM})$ at $96 \mathrm{~h}$ post-transfec- 
A

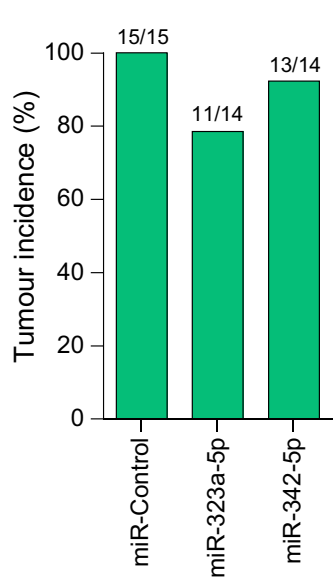

E

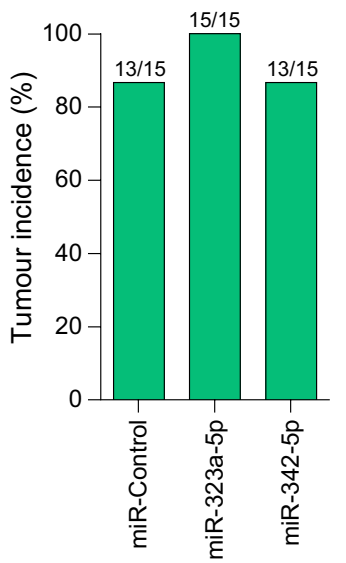

B

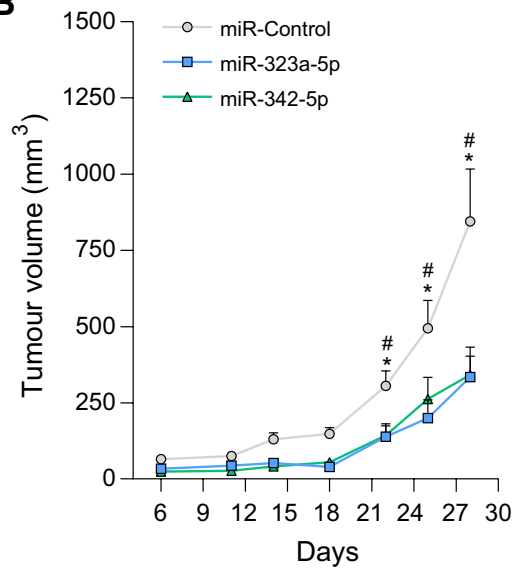

$\mathbf{F}$

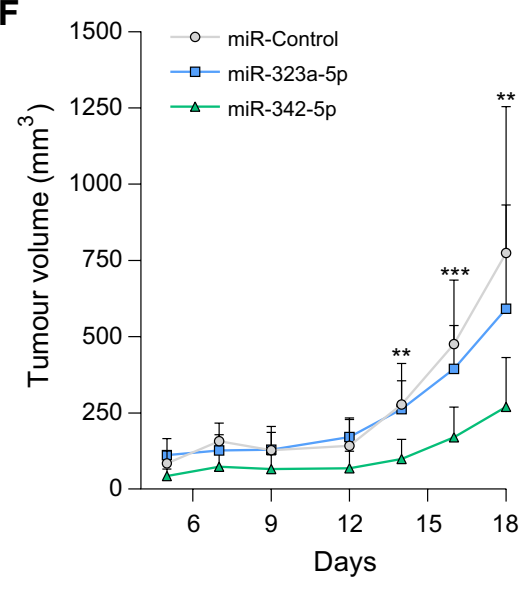

C

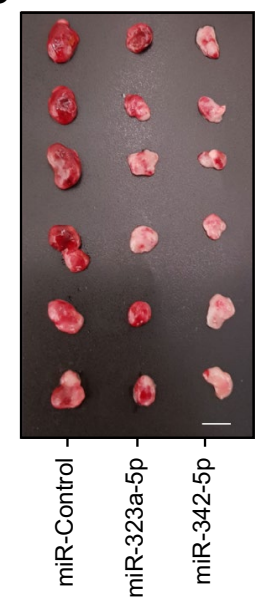

G

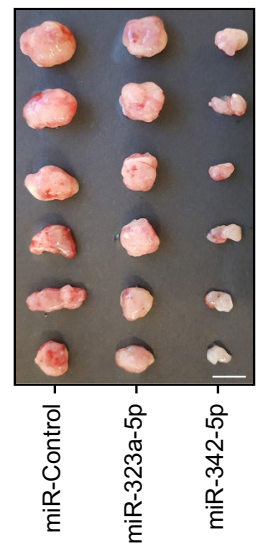

D

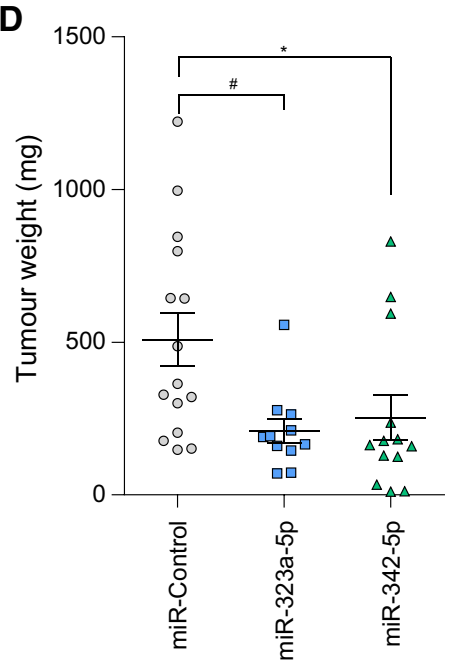

H

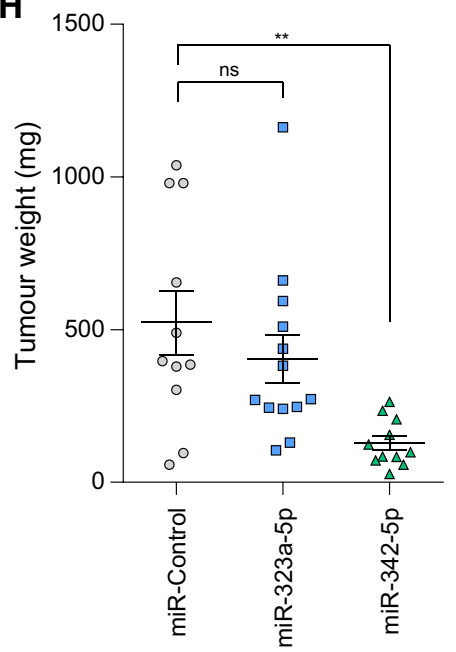

Fig. 7 MiR-323a-5p and MiR-342-5p overexpression reduced tumor growth in vivo. a, e Tumor formation incidence in SK-N-BE(2) (a) and SK-N-AS (e). b, f Tumor growth of xenografts derived from SK-N-BE(2) (b) SK-N-AS (f) cells transfected with miR-control, miR-323a-5p or miR-342-5p. Tumor measurements were taken three

the direct modulation of several cell cycle-associated genes such as CCND1, CHAFIA, INCENP and FADD and caused a G1 cell cycle arrest followed by induction of apoptosis. The silencing of the miR-323a-5p direct targets CHAF1A, INCENP and CCND1 were those that more closely recapitulate the phenotypic effects of miR$323 \mathrm{a}-5 \mathrm{p}$ overexpression. CCND1 is a well-established oncogene frequently overexpressed and associated with poor outcome in different types of tumors including NB [25]. CCND1 interacts with CDK4 and CDK6 and the activation of this complex phosphorylates RB and other transcription factors which promote cell cycle progression [26]. To date, the best approach to targeting CCND1 is through the use of CDK4/6 inhibitors such as palbociclib, ribociclib and abemaciclib. times per week for $\sim 3$ weeks. c, $\mathbf{g}$ Representative images of dissected tumors (bar indicates $1 \mathrm{~cm}$ ). d, h Tumor weight at 18 days post-injection. Hash compares miR-323a-5p versus control and asterisk compares miR-342-5p versus control. ${ }^{*}$ or ${ }^{\#} p<0.05, * * p<0.01$, $* * * p<0.001$, two-tailed Student's $t$ test

Although the best known functions of CCND1 are related to cell cycle control, CCND1 has CDK-independent functions. For example, CCND1 regulates cell differentiation by binding to several transcription factors such as the estrogen receptor $\alpha(\mathrm{ER} \alpha)$ and the androgen receptor (AR) (reviewed in [27]). Therefore, a direct inhibition of CCND1 could be therapeutically more effective than CDK4/6 inhibition.

Another of the newly identified relevant miR-323a-5p target is CHAF1A, a chromatin modifier protein recently involved in maintaining the undifferentiated state of highly aggressive NB [28]. Thus, in addition to halting cell cycle progression, miR-323a-5p could also be relevant for NB therapy through repressing the expression of genes that block the differentiation of NB cells. 
The silencing of INCENP phenocopied the apoptosis induction of miR-323a-5p overexpression. INCENP (inner centromere protein) is a component of the chromosomal passenger complex (CPC), a complex that regulates mitosis. INCENP is a scaffolding subunit for the CPC and activates Aurora B kinase [29]. Similar to CHAF1A, high levels of INCENP in primary NB tumors are associated with poor prognosis (Supplementary Table 6). In addition, silencing of INCENP using doxycycline-inducible shRNA led to significant decreases in growth of NB xenografts and increases mice survival (Sun et al. Advances in Neuroblastoma Research 2018). Therefore, targeting INCENP could be a novel promising therapy in NB.

Our in vivo studies suggested that the transient overexpression of miR-323a-5p was enough to halt the proliferation of MYCN-amplified NB cells but not in SK-N-AS xenograft models, probably due to a higher rate of miRNA processing. At that point, and owing to technical limitations, the fact that more sustained overexpression of miR-323a-5p could have a better therapeutic response cannot be ruled out.

In contrast, the transient overexpression of miR-342-5p did show faster induction of cell death in vitro and a clear reduction in tumor growth in vivo in both NB xenografts tested. In line with our observations, miR-342-5p was reported to be downregulated in breast cancer patients with early relapse [22] and was able to reduce HER2-positive breast cancer cell growth [23] and colon cancer cells [24].

Interestingly, we found that miR-342-5p is also a direct modulator of CCND1. CCND1 silencing alone caused a dramatic decrease in NB cell proliferation, but was not enough to induce cell death (Fig. 6c, f). We also identified BCL-XL as a direct target of miR-342-5p. BCL-XL is an anti-apoptotic member of the B cell lymphoma 2 (BCL-2) protein family whose overexpression contributes to tumor progression and resistance to chemotherapeutic agents [30]. Although $\mathrm{BCL}-\mathrm{XL}$ reduction alone only causes a minimal reduction in cell number and did not induce cell death (Fig. 6f), it may lower the threshold of apoptosis induction upon CCND1 silencing or inhibition. Therefore, the concomitant reduction in CCND1 and BCL-XL would more faithfully reproduce the overexpression effects of miR-342-5p.

\section{Conclusions}

Our strategy is confirmed as valid for the identification of novel tumor-suppressive miRNA such as miR-323a-5p and miR-342-5p in NB models, including but not limited to the ones that are resistant to conventional therapies and reveals new vulnerabilities of high-risk NB through the combined inhibition of targets such as CCND1, CHAF1A, INCENP and BCL-XL.
Acknowledgements We thank members of Laboratory Animal Service and Statistics and Bioinformatics Unit of Vall d'Hebron Research Institute and the staff of Biomolecular Screening and Protein Technologies Unit of Centre for Genomic Regulation. We thank Ms. Christine O'Hara for text correction.

Author contributions AS and MFS designed the study. MM, AS, AB, LPC, CJ and MFS performed the experiments. NM and AS collaborated in cell cycle analysis. AS, MM, OP, RLS, FW, KOH and CS analyzed the data. JST, SG provided intellectual support and expertise toward interpretation of results. MM and MFS wrote the original manuscript. All authors contributed to the edition and the critical review of the manuscript.

Funding The funding was received by Ministerio de Educación, Cultura y Deporte (Grant no. FPU16/01099), Instituto de Salud Carlos III (Grant no. CP11/00052), Instituto de Salud Carlos III (Grant no. CP16/00006), Instituto de Salud Carlos III (Grant no. PI14/00561), Instituto de Salud Carlos III (Grant no. PI14/00647), Instituto de Salud Carlos III (Grant no. PI17/00564), Instituto de Salud Carlos III (Grant no. RD12/0036/0016), FP7 People: Marie-Curie Actions (Grant no. MIRNATHERAPYNBL_PEOPLE-2013-GIC), Fundación Científica Asociación Española Contra el Cáncer (Grant no. AECC-JB-2012-01), AGAUR (Grant no. 2014 SGR 660), Asociación Acunapatata and Asociación NEN.

Open Access This article is distributed under the terms of the Creative Commons Attribution 4.0 International License (http://creativeco mmons.org/licenses/by/4.0/), which permits unrestricted use, distribution, and reproduction in any medium, provided you give appropriate credit to the original author(s) and the source, provide a link to the Creative Commons license, and indicate if changes were made.

\section{References}

1. Maris JM, Kyemba SM, Rebbeck TR, White PS, Sulman EP, Jensen SJ, Allen C, Biegel JA, Brodeur GM (1997) Molecular genetic analysis of familial neuroblastoma. Eur J Cancer 33(12):1923-1928. https://doi.org/10.1016/S0959-8049(97)00265 $-7$

2. Gatta G, Ferrari A, Stiller CA, Pastore G, Bisogno G, Trama A, Capocaccia R (2012) Embryonal cancers in Europe. Eur J Cancer 48(10):1425-1433

3. Bartel DP (2009) MicroRNAs: target recognition and regulatory functions. Cell 136(2):215-233

4. Peng Y, Croce CM (2016) The role of MicroRNAs in human cancer. Signal Transduct Target Ther 1:15004. https://doi. org/10.1038/sigtrans.2015.4

5. Stallings RL (2009) MicroRNA involvement in the pathogenesis of neuroblastoma: potential for microRNA mediated therapeutics. Curr Pharm Des 15(4):456-462

6. Lin RJ, Lin YC, Chen J, Kuo HH, Chen YY, Diccianni MB, London WB, Chang $\mathrm{CH}$, Yu AL (2010) microRNA signature and expression of Dicer and Drosha can predict prognosis and delineate risk groups in neuroblastoma. Cancer Res 70(20):7841-7850

7. Creevey L, Ryan J, Harvey H, Bray IM, Meehan M, Khan AR, Stallings RL (2013) MicroRNA-497 increases apoptosis in MYCN amplified neuroblastoma cells by targeting the key cell cycle regulator WEE1. Mol Cancer 12:23

8. Soriano A, Paris-Coderch L, Jubierre L, Martinez A, Zhou X, Piskareva O, Bray I, Vidal I, Almazan-Moga A, Molist C, Roma J, Bayascas JR, Casanovas O, Stallings RL, Sanchez de Toledo J, Gallego S, Segura MF (2016) MicroRNA-497 impairs the growth 
of chemoresistant neuroblastoma cells by targeting cell cycle, survival and vascular permeability genes. Oncotarget 7(8):92719287. https://doi.org/10.18632/oncotarget.7005

9. Wang Y, Luo J, Zhang H, Lu J (2016) microRNAs in the same clusters evolve to coordinately regulate functionally related genes. Mol Biol Evol 33(9):2232-2247

10. Hoshi M, Otagiri N, Shiwaku HO, Asakawa S, Shimizu N, Kaneko Y, Ohi R, Hayashi Y, Horii A (2000) Detailed deletion mapping of chromosome band 14q32 in human neuroblastoma defines a 1.1$\mathrm{Mb}$ region of common allelic loss. Br J Cancer 82(11):1801-1807. https://doi.org/10.1054/bjoc.2000.1108

11. Kanehisa M, Goto S (2000) KEGG: kyoto encyclopedia of genes and genomes. Nucleic Acids Res 28(1):27-30

12. Boloix A, Paris-Coderch L, Soriano A, Roma J, Gallego S, Sanchez de Toledo J, Segura MF (2015) Novel micro RNA-based therapies for the treatment of neuroblastoma. An Pediatr (Barc). https://doi.org/10.1016/j.anpedi.2015.07.016

13. Daige CL, Wiggins JF, Priddy L, Nelligan-Davis T, Zhao J, Brown D (2014) Systemic delivery of a miR34a mimic as a potential therapeutic for liver cancer. Mol Cancer Ther 13(10):2352-2360. https://doi.org/10.1158/1535-7163.mct-14-0209

14. Beg MS, Brenner AJ, Sachdev J, Borad M, Kang YK, Stoudemire J, Smith S, Bader AG, Kim S, Hong DS (2017) Phase I study of MRX34, a liposomal miR-34a mimic, administered twice weekly in patients with advanced solid tumors. Investig New Drugs 35(2):180-188. https://doi.org/10.1007/s1063 7-016-0407-y

15. Reid G, Kao SC, Pavlakis N, Brahmbhatt H, MacDiarmid J, Clarke S, Boyer M, van Zandwijk N (2016) Clinical development of TargomiRs, a miRNA mimic-based treatment for patients with recurrent thoracic cancer. Epigenomics 8(8):1079-1085. https:// doi.org/10.2217/epi-2016-0035

16. Thakral S, Ghoshal K (2015) miR-122 is a unique molecule with great potential in diagnosis, prognosis of liver disease, and therapy both as miRNA mimic and antimir. Curr Gene Ther 15(2):142-150

17. Powers JT, Tsanov KM, Pearson DS, Roels F, Spina CS, Ebright R, Seligson M, de Soysa Y, Cahan P, Theissen J, Tu HC, Han A, Kurek KC, LaPier GS, Osborne JK, Ross SJ, Cesana M, Collins JJ, Berthold F, Daley GQ (2016) Multiple mechanisms disrupt the let-7 microRNA family in neuroblastoma. Nature 535(7611):246251. https://doi.org/10.1038/nature18632

18. Beckers A, Van Peer G, Carter DR, Mets E, Althoff K, Cheung BB, Schulte JH, Mestdagh P, Vandesompele J, Marshall GM, De Preter K, Speleman F (2015) MYCN-targeting miRNAs are predominantly downregulated during MYCN driven neuroblastoma tumor formation. Oncotarget 6(7):5204-5216. https://doi. org/10.18632/oncotarget.2477

19. Schulte JH, Marschall T, Martin M, Rosenstiel P, Mestdagh P, Schlierf S, Thor T, Vandesompele J, Eggert A, Schreiber S, Rahmann S, Schramm A (2010) Deep sequencing reveals differential expression of microRNAs in favorable versus unfavorable neuroblastoma. Nucleic Acids Res 38(17):5919-5928. https://doi. org/10.1093/nar/gkq342

20. Bray I, Bryan K, Prenter S, Buckley PG, Foley NH, Murphy DM, Alcock L, Mestdagh P, Vandesompele J, Speleman F, London
WB, McGrady PW, Higgins DG, O’Meara A, O’Sullivan M, Stallings RL (2009) Widespread dysregulation of MiRNAs by MYCN amplification and chromosomal imbalances in neuroblastoma: association of miRNA expression with survival. PLoS One 4(11): 7850

21. Yang HA, Wang X, Ding F, Pang Q (2015) MiRNA-323-5p promotes U373 cell apoptosis by reducing IGF-1R. Med Sci Monit Int Med J Exp Clin Res 21:3880-3886

22. Perez-Rivas LG, Jerez JM, Carmona R, de Luque V, Vicioso L, Claros MG, Viguera E, Pajares B, Sanchez A, Ribelles N, Alba E, Lozano J (2014) A microRNA signature associated with early recurrence in breast cancer. PLoS One 9(3):e91884. https://doi. org/10.1371/journal.pone.0091884

23. He YJ, Wu JZ, Ji MH, Ma T, Qiao EQ, Ma R, Tang JH (2013) miR-342 is associated with estrogen receptor-alpha expression and response to tamoxifen in breast cancer. Exp Ther Med 5(3):813818. https://doi.org/10.3892/etm.2013.915

24. Yang H, Li Q, Niu J, Li B, Jiang D, Wan Z, Yang Q, Jiang F, Wei P, Bai S (2016) microRNA-342-5p and miR-608 inhibit colon cancer tumorigenesis by targeting NAA10. Oncotarget 7(3):2709_ 2720. https://doi.org/10.18632/oncotarget.6458

25. Molenaar JJ, Ebus ME, Koster J, van Sluis P, van Noesel CJ, Versteeg R, Caron HN (2008) Cyclin D1 and CDK4 activity contribute to the undifferentiated phenotype in neuroblastoma. Cancer Res 68(8):2599-2609. https://doi.org/10.1158/0008-5472. can-07-5032

26. Lukas J, Muller H, Bartkova J, Spitkovsky D, Kjerulff AA, JansenDurr P, Strauss M, Bartek J (1994) DNA tumor virus oncoproteins and retinoblastoma gene mutations share the ability to relieve the cell's requirement for cyclin D1 function in G1. J Cell Biol 125(3):625-638

27. Bienvenu F, Jirawatnotai S, Elias JE, Meyer CA, Mizeracka K, Marson A, Frampton GM, Cole MF, Odom DT, Odajima J, Geng Y, Zagozdzon A, Jecrois M, Young RA, Liu XS, Cepko CL, Gygi SP, Sicinski P (2010) Transcriptional role of cyclin D1 in development revealed by a genetic-proteomic screen. Nature 463(7279):374-378. https://doi.org/10.1038/nature08684

28. Barbieri E, De Preter K, Capasso M, Chen Z, Hsu DM, Tonini GP, Lefever S, Hicks J, Versteeg R, Pession A, Speleman F, Kim ES, Shohet JM (2014) Histone chaperone CHAF1A inhibits differentiation and promotes aggressive neuroblastoma. Cancer Res 74(3):765-774. https://doi.org/10.1158/0008-5472.can-13-1315

29. Gohard FH, St-Cyr DJ, Tyers M, Earnshaw WC (2014) Targeting the INCENP IN-box-Aurora B interaction to inhibit CPC activity in vivo. Open Biol 4(11):140163. https://doi.org/10.1098/ rsob.140163

30. Decaudin D, Geley S, Hirsch T, Castedo M, Marchetti P, Macho A, Kofler R, Kroemer G (1997) Bcl-2 and Bcl-XL antagonize the mitochondrial dysfunction preceding nuclear apoptosis induced by chemotherapeutic agents. Cancer Res 57(1):62-67

Publisher's Note Springer Nature remains neutral with regard to jurisdictional claims in published maps and institutional affiliations. 